\title{
A TERRITORIALIDADE DAS ORDENS LEIGAS E A CONFIGURAÇÃO URBANA DO CENTRO DA CIDADE DO RIO DE JANEIRO NO SÉCULO XVIII
}

- CLAUDIA BARBOSA TEIXEIRA ${ }^{1}$

RESUMO: A CONFIGURAÇÃO URBANA DA ÁREA CENTRAL DA CIDADE DO RIO DE JANEIRO, ENTRE OUTROS, FOI PERMEADA PELA RELIGIOSIDADE DE SEUS HABITANTES, QUE EM MUITOS CASOS REUNIAM-SE EM ASSOCIAÇÕES RELIGIOSAS QUE EXERCERAM UM IMPORTANTE PAPEL SOCIAL, POLÍTICO E ECONÔMICO NA SOCIEDADE CARIOCA NO SÉCULO XVIII. O PRESENTE ARTIGO TEM POR OBJETIVO APONTAR ESSAS ASSOCIAÇÕES CONHECIDAS COMO ORDENS LEIGAS - ORDENS TERCEIRAS E IRMANDADES - QUE NO EXERCÍCIO DE SUA TERRITORIALIDADE, DESPONTARAM COMO UM DOS AGENTES DE FORMAÇÃO DA MALHA URBANA DO CENTRO DA CIDADE PARA FORA DOS LIMITES ESTABELECIDOS ATÉ O FINAL DO SÉCULO XVIII. PARA TANTO, APONTOU-SE AS AÇÕES ESTRATÉGICAS DESSAS ASSOCIAÇÕES QUE COM SUAS PRÁTICAS DEVOCIONAIS COMO PROCISSÕES, FESTAS E PEREGRINAÇÕES, SE APROPRIARAM DO TERRITÓRIO DO CAMPO DA CIDADE, REGIÃO DE EXPANSÃO DO NÚCLEO CENTRAL.

PALAVRAS-CHAVE: ORDENS LEIGAS. TERRITORIALIDADE. RIO DE JANEIRO. SÉCULO XVIII.

Desde a fundação da cidade do Rio de Janeiro, em 1565, a Igreja Católica ocupou importantes territórios no solo carioca. Independente de quem foi a iniciativa da construção religiosa da ermida, da capela, da igreja, ou do complexo religioso, era a Igreja Católica que se estruturava e se fazia representar através da 
arquitetura, dos símbolos e das práticas religiosas ali exercidas. Até meados do século XVIII verificou-se no núcleo central, formado pelo perímetro delimitado por quatro morros, que foram erguidos 44 templos, sendo 24 destes por iniciativa das Ordens Leigas $^{2}$ além de edificações religiosas como conventos e seminários que espelhavam o poder religioso e territorial da Instituição.

O presente artigo tem por objetivo apresentar o processo de territorialização da Igreja Católica na área de expansão do núcleo central da cidade do Rio de Janeiro, através da atuação das primeiras Ordens Leigas, em sua maioria Irmandades de negros, que se implantaram na região no século XVIII. São elas as Irmandades de São Domingos de Gusmão, de Santana, de Santa Efigênia e Santo Elesbão, de Nossa Senhora da Lampadosa, de São Jorge, de São Gonçalo Garcia e a Ordem Terceira dos Mínimos de São Francisco de Paula. Optouse pela abordagem cultural em sua dimensão espacial, mais especificamente do ramo da geografia da religião, na linha de investigação religião, território $e$ territorialidade.

\section{Conceitos de Território e} Territorialidade

Para o geógrafo americano Robert Sack (1986) o território surge da tentativa, por um individuo ou grupo, de afetar, influenciar ou controlar pessoas, fenômenos e relacionamentos, através da delimitação e afirmação do controle sobre uma área geográfica.

$$
\begin{aligned}
& \text { "Diferentemente de } \\
& \text { outros lugares comuns, } \\
& \text { territórios requerem um } \\
& \text { constante esforço para se } \\
& \text { estabelecer e manter. Eles } \\
& \text { são resultados das } \\
& \text { estratégias para afetar, } \\
& \text { influenciar e controlar" } \\
& \text { (SACK, 1986, p.19). }
\end{aligned}
$$

A partir do conceito de território, Rosendahl (2006) definiu território religioso como o

$$
\begin{aligned}
& \text { "território demarcado, no } \\
& \text { qual o acesso é } \\
& \text { controlado e dentro do } \\
& \text { qual a autoridade é } \\
& \text { exercida por um } \\
& \text { profissional religioso. É } \\
& \text { dotado de estruturas } \\
& \text { específicas, incluindo um } \\
& \text { modo de distribuição } \\
& \text { espacial e de gestão do } \\
& \text { sagrado". }
\end{aligned}
$$

Serão considerados territórios religiosos as propriedades das Ordens Leigas citadas, constituídas pelas igrejas e seus respectivos terrenos.

No caso de algumas Irmandades, especialmente as constituídas por negros, a posse de um terreno em uma localização inóspita, ainda sem qualquer tipo de infraestrutura urbana, requereu um esforço significativo para manter e controlar a área 
e dar a essa área a identidade do grupo, isto é, imprimir no lugar os elementos simbólicos de sua identidade religiosa. Para os fiéis das Irmandades, particularmente a dos negros e pardos, a posse de um território não significava apenas seu valor material, mas principalmente um espaço de convivência, de aceitação, de pertença, de auxílio mútuo e de vivência de sua religiosidade. O poder religioso no lugar, no território.

Complementando os conceitos de território e território religioso tornou-se igualmente importante e necessário a definição de territorialidade na abordagem da geografia, uma vez que se pretende demonstrar que foi a partir desta ação estratégica que as Ordens Leigas, com sua dinâmica, configuraram um singular arranjo espacial urbano na cidade. Robert Sack adaptou o conceito de territorialidade para humanos, ressaltando que estes também podem utilizá-la por razões abstratas. Para o autor:

[...]Territorialidade para humanos é uma estratégia geográfica poderosa para controlar pessoas e coisas pelo controle da área. Territórios políticos e propriedade privada da terra podem ser suas formas mais conhecidas, mas a territorialidade ocorre em graus variados em diversos contextos sociais. Seu uso ocorre em relações cotidianas e em organizações complexas. É o meio pelo qual espaço e sociedade se inter-relacionam. As mudanças de função da territorialidade nos ajudam a entender as relações históricas entre sociedade, espaço e tempo (SACK, 1986, p.5).

A territorialidade resultaria de uma construção social onde o indivíduo ou o grupo ocupante de um determinado território, através de suas relações sociais, estabelecem identidade com ele, sendo reconhecidos como originais do mesmo. Sack aponta que diferentes sociedades apresentam organizações espaciais e concepções de espaço e lugar diferentes, de acordo com a história de cada sociedade. Portanto, para fins desse estudo, territorialidade deve ser entendida como uma ação estratégica de controle, produto das relações e práticas desenvolvidas por um grupo religioso que afetou, influenciou e colaborou na manutenção de seu território.

Como complementação do conceito de territorialidade, Rosendahl também definiu o que é territorialidade religiosa:

Territorialidade religiosa na abordagem da 


geografia cultural
significa o conjunto de
práticas desenvolvidas
por instituições ou grupos
religiosos no sentido de
controlar pessoas e
objetos num dado
território religioso. É uma
ação para manter a
existência, legitimar a fé
e a sua reprodução ao
longo da história da Igreja
Católica no Brasil
(ROSENDAHL, 2008,
p.57).

De acordo com esse raciocínio, se pretende demonstrar que $\mathrm{o}$ fato da Irmandade religiosa ter adquirido seu território e construído seu templo influenciou as ações da administração pública da cidade do Rio de Janeiro com relação à área circunvizinha. Com as práticas religiosas exercidas no espaço da igreja, tais como os cultos de devoção, as procissões, as festas e demais ações como melhoramentos do templo e da área de entorno foram estratégias executadas pelos fiéis para se manter o território. O sistema de práticas e crenças religiosas estabelecido no território religioso afetaria não só o comportamento social do grupo como de outros moradores da cidade.

As estratégias de controle deverão ser aliadas à dimensão política e sócioreligiosa do grupo social envolvido. $\mathrm{Ou}$ seja, no caso da presente pesquisa será demonstrado como as características sociais, culturais e étnicas de cada Irmandade analisada determinaram suas ações no espaço viabilizando a manutenção de seu território. Nos exemplares das instituições a serem analisadas nesse artigo, os territórios se encontram totalmente identificados com símbolos, imagens e práticas religiosas católicas, que serão descritas a seguir.

As ações estratégicas e o conjunto de práticas religiosas das Ordens Leigas

No período escolhido para análise, a sociedade carioca, independente de sua condição social, participava ativamente da vida religiosa, sendo reconhecida a pluralidade das práticas e atividades exercidas ao longo do ano. A Igreja Católica fornecia uma identidade religiosa aos fiéis e esses fiéis manifestavam sua identidade religiosa na Instituição. Qualidades presentes e necessárias ao sucesso da fé nos territórios religiosos selecionados.

A vivência do tempo sagrado, as manifestações exteriores da fé, os ritos, a devoção aos santos, e demais práticas religiosas foram ações estratégicas incentivadas pela instituição católica para conversão e manutenção dos fiéis e conquista do território. Os fiéis, por sua vez, se apropriaram dessas práticas, dando a 
elas maior ou menor significado de acordo com as características próprias de seu grupo. Organizadamente, nas Irmandades, esses fiéis católicos conseguiram ao longo do tempo, recolher fundos que permitiram a aquisição de um território e a construção de seu próprio templo, o que possibilitou novas festas, novas celebrações litúrgicas, novos membros. Destacam-se como manifestações religiosas no espaço carioca, para fins desse estudo, duas práticas devocionais que permitiram uma contínua vida de conversão da fé católica: as festas dedicadas aos santos e as procissões. Refletir sobre esse tempo de festas em nossa análise favorece reconhecer as ações e suas manifestações no território religioso.

A territorialidade de cada Ordem Leiga com seus espaços ocupados por celebrações, seus trajetos pelas ruas em dias de festa, fez com que os acessos e a área circunvizinha ao templo fossem melhorando de qualidade a cada ano, em uma cidade cuja responsabilidade por benfeitorias era mais da população do que da administração. Analisar-se-á a seguir a configuração da malha urbana da área do Campo da Cidade, até o ano de 1763, a fim de identificar o início do processo de ocupação da região de expansão do centro da cidade a partir das primeiras igrejas ali implantadas.

\section{A configuração urbana do Campo da} Cidade até $\mathbf{1 7 6 3}$
O Conde de Bobadela, em sua gestão no governo (1733-1763), executou uma série de melhoramentos que rascunhavam certa ordenação urbana. Em sua administração proliferaram Ordens Leigas, principalmente Irmandades. Muitas delas iniciaram a construção de suas igrejas na região de interesse - o Campo da Cidade - no período em análise: a de são Domingos de Gusmão, a de Santana, a de Santa Efigênia e Santo Elesbão, a de Nossa Senhora da Lampadosa, de São Jorge, de São Gonçalo Garcia e a de São Francisco de Paula.

Foram executadas outras construções religiosas, como por exemplo, o seminário de São José e o seminário de Nossa Senhora da Lapa do Desterro. Além dos conventos da Ajuda e de Santa Teresa. Porém, a obra mais significativa para esta pesquisa é a da Sé Catedral, por estar localizada na área de expansão do centro da cidade e ter sido uma das construções que influenciaram diretamente a sua ocupação, conforme nossa análise.

A história de construir uma nova catedral para a cidade vinha sendo desejada desde meados do século XVII, devido ao mau estado da igreja de São Sebastião no alto do morro de São Januário. Em 1734, o bispo D. Antônio de Guadalupe, que não se conformava em celebrar missas em uma igreja em mau estado de conservação, se transferiu para a igreja de Nossa Senhora do Rosário e São Benedito dos Homens Pretos, 
o que gerou conflitos com a Irmandade. Após alguns anos, o rei D. João $\mathrm{V}$ atendeu às solicitações dos bispos do Rio de Janeiro e, finalmente, permitiu a busca de um terreno para construção de uma Sé Catedral. O poder político - Governador Conde de Bobadela, o poder religioso - bispo Dom Frei Antônio do Desterro Malheiros e o poder militar - brigadeiro José Fernandes Pinto Alpoim acolheram o pedido e escolheram um local para erguer a catedral. O sítio escolhido se localizava fora das muralhas da cidade, por detrás da igreja do Rosário. Cavalcanti (2004, p.344) relata que "em 7 de maio de 1748 realizou-se a cerimônia de concorrência pública para a $1^{\mathrm{a}}$ etapa da obra", que foi paralisada em 1754 por falta de verbas, devido principalmente ao custeio das guerras no sul do país, ocasionado pela demarcação de fronteiras, conforme registram os documentos.

O período de execução das obras iniciais da Catedral, de 1749 a 1754, foi um marco na vida urbana, pois favoreceu a atenção da população sobre uma região adjacente à malha urbana já consolidada. Esta recebeu a denominação de Largo da Sé Nova, posteriormente Largo Real da Sé. Em 1756, no mesmo largo, se iniciaram as obras da igreja da Ordem Terceira dos Mínimos de São Francisco de Paula. Tempos depois o santo deu nome ao largo e assim permanece até hoje. A escolha para construir a Catedral $^{3}$ da cidade, maior símbolo arquitetônico de expressão da fé católica em uma área de expansão do núcleo central, fora dos muros e dos limites fixados até então, aponta que a implantação de um território religioso por iniciativa dos poderes religiosos, político e militar foi estratégia determinante para a ocupação do Campo da Cidade. Nessa região, até o início das obras de construção da catedral (1749), já se encontravam edificadas as igrejas de São Domingos de Gusmão e de Santana.

O chamado Campo da Cidade era uma área pública, ainda inabitada que se estendia da rua da Vala, atual rua Uruguaiana, até o mangue de São Diogo ${ }^{4}$ :

$$
\begin{aligned}
& \text { "um vasto descampado, } \\
& \text { planura semeada de } \\
& \text { charcos, brejos e alagados } \\
& \text { pelo meio dos quais } \\
& \text { serpenteava o Caminho } \\
& \text { de Capueraçu que } \\
& \text { conduzia às fazendas } \\
& \text { açucareiras dos Jesuítas - } \\
& \text { Engenho Velho e } \\
& \text { Engenho Novo" } \\
& \text { (COARACY, 2008, } \\
& \text { p.41). }
\end{aligned}
$$

Era esse rossio que os moradores soltavam seu gado para pasto, o "quintal da povoação", como demonstra o Mapa 1. Diversos autores afirmam que no início do século XVIII foi solicitada à Câmara a concessão, por aforamento, de áreas de terras nesse Campo para implantação de chácaras visando criações e plantações. Alguns moradores menos abastados 
Mapa 1 - Campo da Cidade e Mangue de São Diogo - início do século XVIII

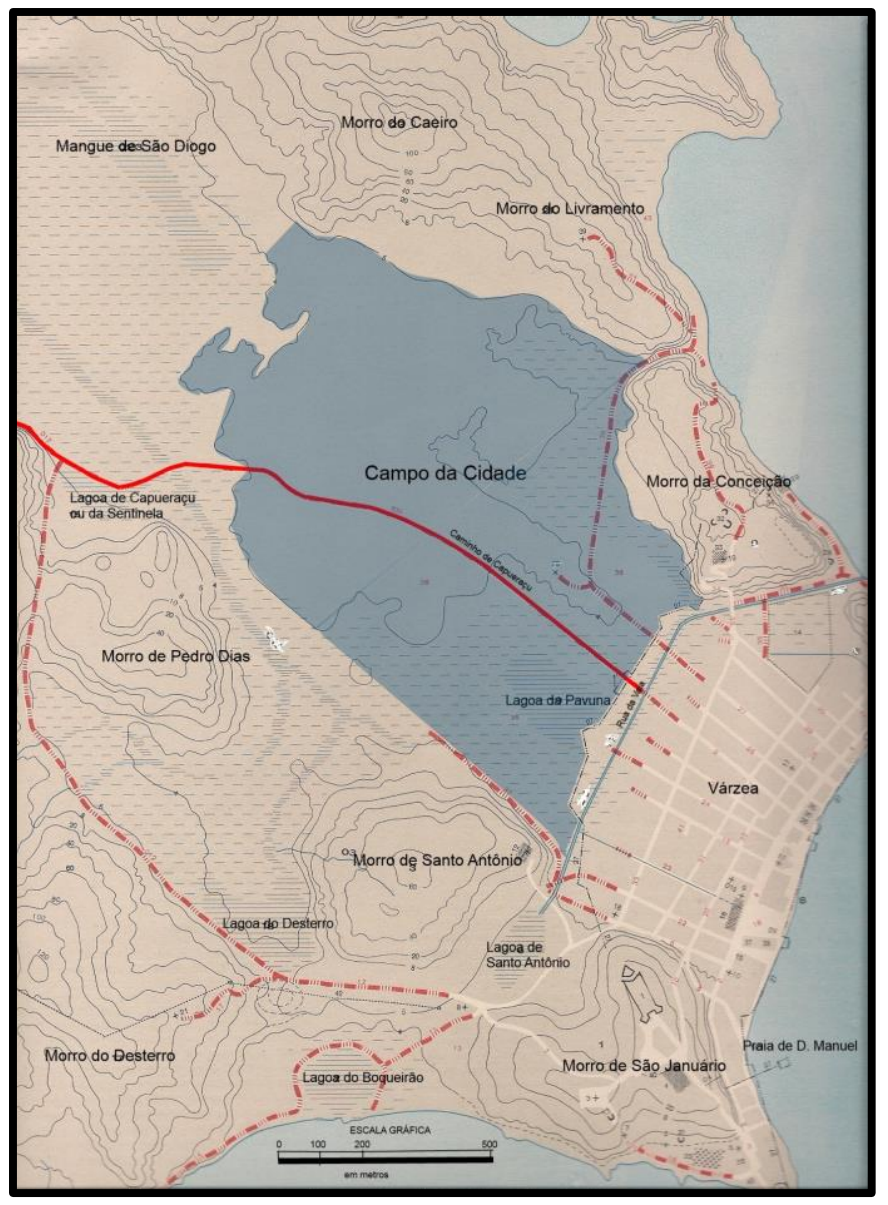

Elaborado por TEIXEIRA, C. a partir da base cartográfica de Barreiros (1965).

Uma das primeiras terras do Campo da Cidade cedidas pela Câmara foi para a Irmandade de São Domingos de Gusmão que pretendia erguer seu próprio templo e implantar seu cemitério. O terreno, que possuía uma área total de $2.516,80 \mathrm{~m}^{2}$, foi doado pelos vereadores em novembro de 1706, sem foro. Os Irmãos construíram sua igreja de São Domingos de Gusmão e por ser a primeira igreja ali instalada e uma das únicas construções na região, esta ficou conhecida como Campo de São Domingos até o início do século XIX. Este

"abrangia toda a área que se estende da atual Praça da República à rua Uruguaiana num sentido, e transversalmente do presente Cais do Porto à Rua do Senado, onde encontra os pantanais de Pedro Dias" 
(COARACY, 2008, p.42).

Não era mais uma vasta extensão contínua e aberta como era o Campo da Cidade, mas designava propriamente um bairro ou região da cidade, tendo sido subdividido em chácaras e moradias ao longo do tempo.
Pelo Mapa 2 fica visível que a igreja de São Domingos foi uma das primeiras construções na região, dando início ao processo de ocupação da área de expansão da cidade. Duas ruas chegavam ao Campo: a do Senhor Bom Jesus e a de São Pedro.

\section{Mapa 2 - Campo de São Domingos - início do século XVIII}

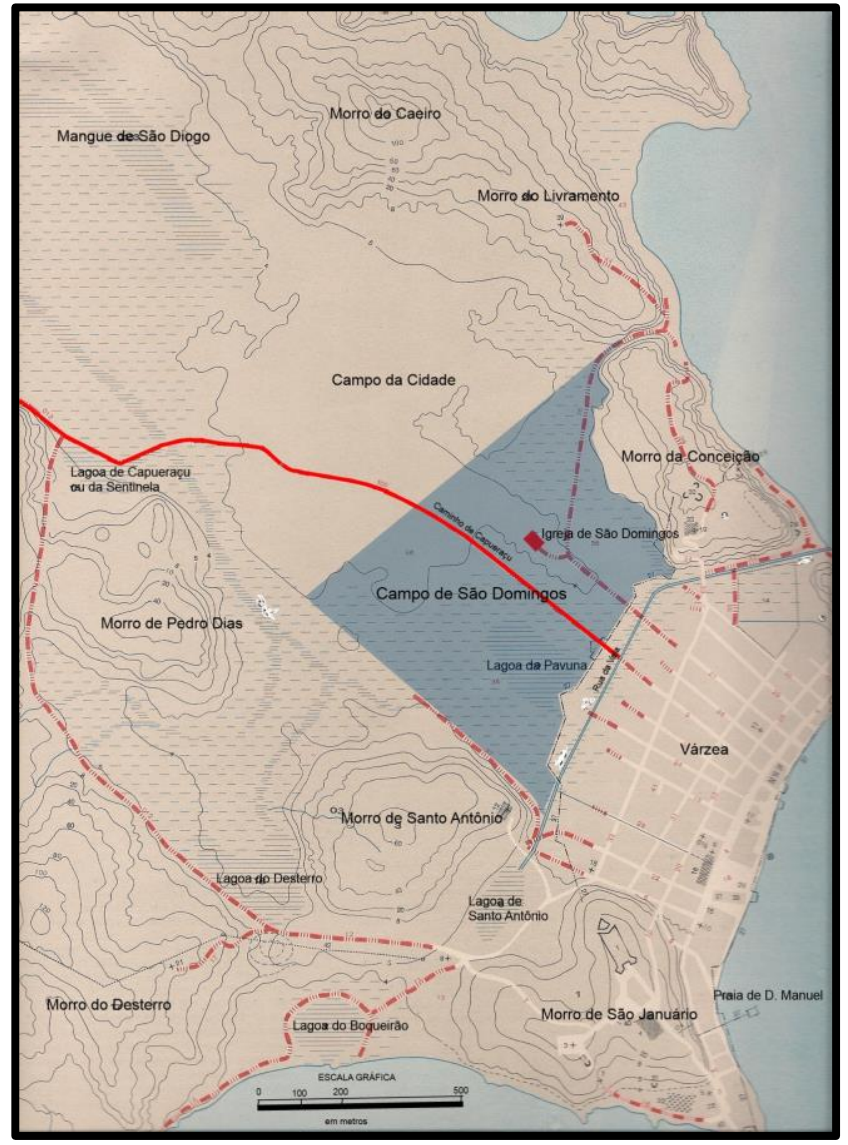

Elaborado por TEIXEIRA, C. a partir da base cartográfica de Barreiros (1965).

Na parte mais distante do Campo da Cidade, limítrofe ao Campo de São Domingos, no início do século XVIII, se formou a chácara do cônego Antônio Pereira da Cunha, arcediago da Sé. Nessa propriedade o cônego ofereceu um terreno à Irmandade de Santana para construção de sua própria igreja. No ano de 1735 a capela estava concluída. A partir da construção do templo, igualmente por se tratar de uma das poucas construções na região, toda essa grande área ficou conhecida como Campo de Santana (atual Praça da República). Conforme demonstrado no Mapa 3, de meados do século XVIII, a presença de construções na região era quase inexistente. 
Mapa 3 - Campo de Santana - 1750

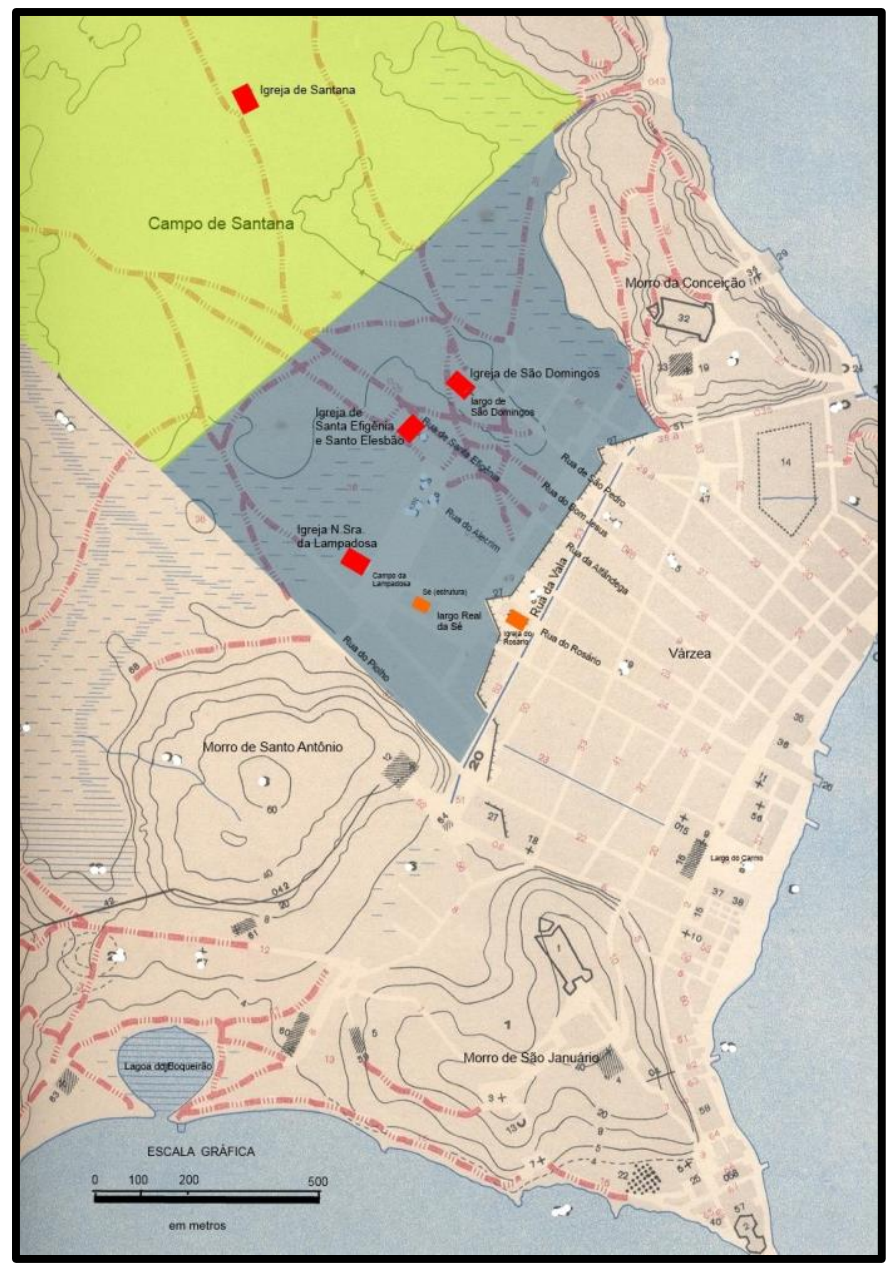

Elaborado por TEIXEIRA, C. a partir da base cartográfica de Barreiros (1965).

Essa modesta capela de Santana erigida em uma região tão remota da cidade foi local de diversas manifestações públicas da fé católica. A partir de suas dependências, ocorriam as missas festivas dedicadas à santa, sempre acompanhadas das práticas religiosas que alimentavam a contínua conversão dos fiéis como procissões, rezas do terço, ladainhas.
De acordo com Fazenda (1921), no mesmo Campo, a Irmandade do Divino Espírito Santo recebeu por doação de Manuel José Martins Gil e sua esposa uma faixa de terreno em sua chácara conhecida como "dos Cajueiros" perfazendo um total de 726,00 m2. O Império, como ficou conhecida a Irmandade, construiu um pavilhão de pedra e cal, com uma capelinha no fundo. Era vizinho da Capela de 
Santana. As práticas religiosas eram bastante populares e atraíam à região boa parte da população vinda de diferentes classes sociais. Um grupo de rapazes saía da igreja de Santana no sábado de Aleluia seguidos pelo "imperador", geralmente escolhido entre os meninos de 12 anos, trajado com

"casaca de veludo
encarnado, calções idem,
meias de seda branca,
cabeleira empoada e de
rabicho, espadim ao lado,
e grande medalhão
pendente no pescoço"
(FAZENDA, 1921, p.
412).

As festividades duravam 50 dias, abrangendo todo o Tempo Pascal, período entre o Domingo de Páscoa e o Domingo de Pentecostes. Este último, pelo tempo litúrgico da Igreja Católica, é o dia onde os cristãos celebram a festa do Espírito Santo, portanto, principal data de atividades para a Irmandade. A festa compreendia a coroação do imperador, seguida de missa. Os festejos duravam três dias, nos quais o personagem principal era obrigado a permanecer para receber as homenagens, esmolas e presidir o leilão das prendas. Havia barraquinhas ao redor do espaço de culto com atividades não religiosas, onde se vendiam petiscos, doces, bebidas e realizavam-se brincadeiras e jogos. A Festa do Divino ainda hoje é celebrada de maneira similar em algumas cidades do Brasil como Goiás, Florianópolis, Paraty, Salvador, Pirenópolis, seguindo a tradição do cortejo e do menino vestido de Imperador.

Naquele tempo só havia um acesso à capela de Santana, chamado Caminho de Capueraçu, que ligava o núcleo urbano às propriedades da Companhia de Jesus. Porém, o culto à Santana e ao Divino Espírito Santo era tão dinâmico e os Irmãos deviam se empenhar tanto nas celebrações que na região já se verificava edificações em seu entorno, mesmo tendo sido próximo dali até o ano da administração do Vice-rei Conde de Resende (1790-1801) local de despejo de detritos.

Instaladas essas duas Irmandades, a de São Domingos de Gusmão e a de Santana, com suas respectivas áreas de abrangência denominadas Campo de São Domingos e Campo de Santana, o que se verificou, através dos mapas foi a implantação gradativa de quarteirões em torno dos templos com o cordeamento ${ }^{5}$ de pequenos logradouros, que viabilizaram o acesso aos mesmos.

A partir da construção das duas igrejas já analisadas, a região recebeu a implantação de outros templos igualmente importantes para a consolidação da malha urbana, como o da Irmandade de Santa Efigênia e Santo Elesbão. A instituição conseguiu, em 1745, um terreno para construção de sua igreja na rua da Alfândega, no Campo de São Domingos. No ano de 1747 foi benzida a pedra 
fundamental. A partir de então esse trecho do Caminho de Capueraçu, compreendido entre as ruas da Conceição e travessa São Domingos denominou-se rua Santa Efigênia, em homenagem à santa. Após anos arrecadando recursos para a construção, o templo foi inaugurado em 28 de agosto de 1754. Junto ao terreno da igreja fundou-se o cemitério, onde tempos depois se passou a enterrar também os escravos que não pertenciam à instituição. Permaneceu em funcionamento até 1850, quando foram proibidos os enterramentos nas igrejas e nos cemitérios contíguos.

Como parte integrante de suas práticas religiosas, além da festa dedicada aos santos, havia outra festa realizada em seguida, em honra a Nossa Senhora dos Remédios, cuja Irmandade também se reunia nesse templo. No ano de 1764, os Irmãos de Santa Efigênia e Santo Elesbão solicitaram permissão para a criação dos cargos de Imperador, Imperatriz, Príncipe e Princesa de Estado. Obtiveram a licença e a vivência no território religioso foi fortalecida por novas práticas. A dramatização oferecida aos fiéis permitia integração social e identidade religiosa dentro da Irmandade.

Igualmente no Campo de São Domingos, no período de governo do Conde de Bobadela, iniciou-se a construção da igreja de Nossa Senhora da Lampadosa. O terreno da igreja, doado por Pedro Coelho da Silva, em 1748, possuía uma área de $726,00 \mathrm{~m}^{2}$. O templo só foi benzido para o culto em 1772, quando uma parte do vasto campo de São Domingos ficou conhecida como Campo da Lampadosa, incluindo o Largo do Rossio, atual Praça Tiradentes. Como Lampadosa também foram denominadas uma rua e uma travessa abertas em torno do templo. Nessa mesma igreja também se encontravam hospedados a Irmandade de São Crispim e São Crispiniano, padroeiros dos sapateiros, e também uma Devoção do Rei Baltazar. Esta última era composta por negros e possuíam a prática de eleger entre seus membros a categoria de Imperador e Imperatriz. A festa era celebrada no dia 6 de janeiro, festa dos Reis Magos, inserida em um importante tempo litúrgico para a Igreja Católica, o Tempo do Natal, Tempo sagrado para os fiéis, onde

$$
\begin{aligned}
& \text { "saía a Devoção à rua, em } \\
& \text { grande folgança, } \\
& \text { cantando e dançando à } \\
& \text { moda da África, com os } \\
& \text { seus instrumentos e os } \\
& \text { seus trajes típicos" } \\
& \text { (COARACY, 2008, p. }
\end{aligned}
$$
45).

O cortejo permitia aos membros da Irmandade serem vistos pelo grupo social do lugar e abriam novos caminhos de sociabilidade no arranjo espacial da urbe carioca. No mapa 4 encontram-se implantadas as igrejas mencionadas acima. 
Mapa 4 - Localização das igrejas construídas até meados do século XVIII

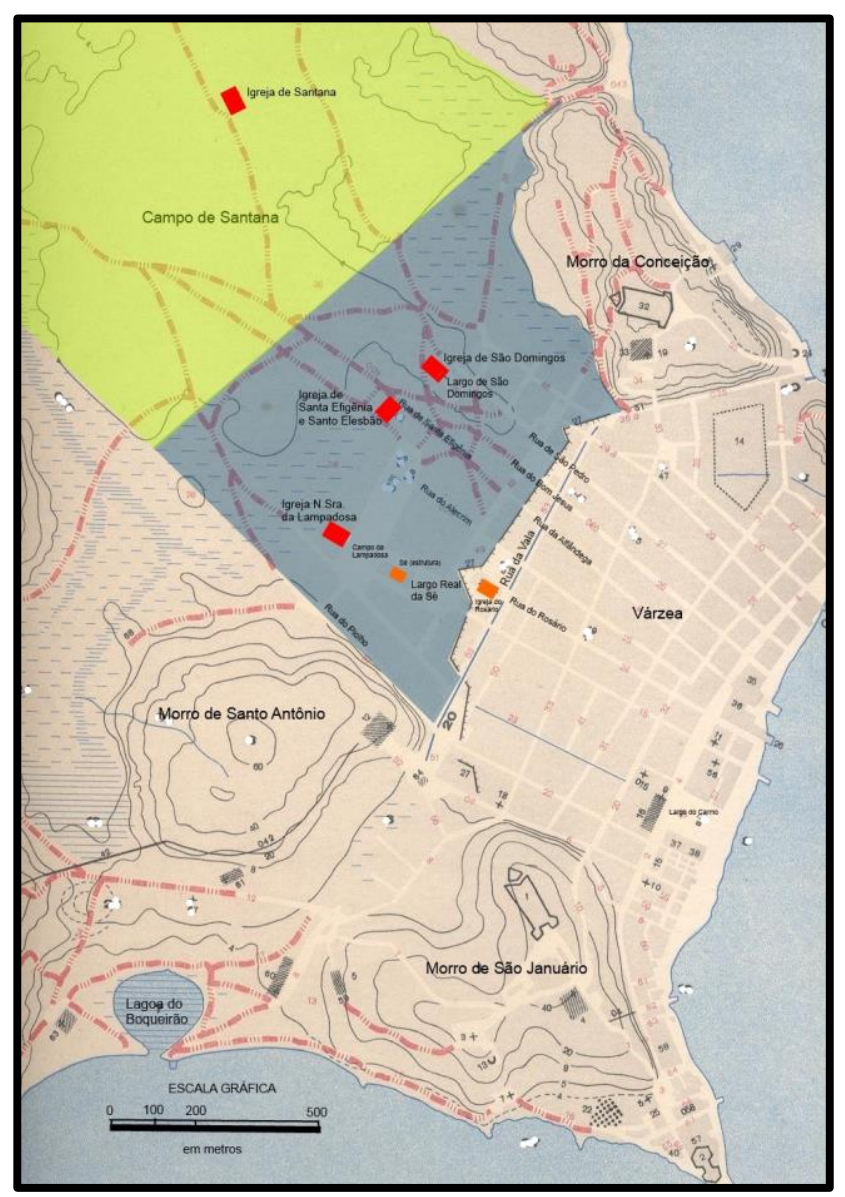

Elaborado por TEIXEIRA, C. a partir da base cartográfica de Barreiros (1965).

Outra importante Irmandade, a de São Jorge, também se implantou na região do Campo da Cidade. O terreno da igreja foi doado por Pedro Coelho da Silva e possuía 13,20 metros de frente por 44 metros de profundidade, perfazendo um total de $580,80 \mathrm{~m}^{2}$. Esse terreno ficava no extremo da chácara do casal, de frente para um caminho de uso público que ligava a região do Rossio ao Caminho de Capueraçu, atual Rua da Alfândega. Esse caminho serviu de alinhamento para a abertura da rua que posteriormente receberia o nome de São Jorge - atual Gonçalves Ledo. Em 1753 permitiu-se a edificação da capela e após receber a doação, a Irmandade adquiriu outro terreno de maiores proporções onde edificou sua igreja, concluída em 1800, quando pode receber a trasladação da imagem, antes guardada nas casas dos Irmãos (ferreiros e caldeireiros).

Das práticas religiosas da Irmandade de São Jorge, merece destaque a mais concorrida: a procissão do dia dedicado ao santo. A imagem de São Jorge era acompanhada de um escudeiro, vestido com a armadura e um grupo de homens vestidos com trajes de gala, montados em cavalos imponentes que arrastavam sobre 
uma carreta a imagem do dragão, morto pelo santo. A procissão apresentava a teatralização do episódio da vida religiosa do Santo e assim permaneceu por muitos anos.

No ano de 1850 a igreja de São Jorge, encontrava-se em ruínas, por não terem realizado as obras necessárias de manutenção do templo, que haveria de ser demolido em 1855. Os Irmãos buscaram asilo na igreja de São Gonçalo Garcia, até conseguirem restaurar o seu próprio templo, o que não ocorreu. Essa igreja da Irmandade de São Gonçalo Garcia havia sido implantada sobre um terreno doado pelo cônego Antônio Lopes Xavier, na atual rua da Alfândega, na esquina com o Campo de Santana. O terreno media 11 metros de frente por 46,20 metros de profundidade, num total de 508,20 $\mathrm{m}^{2}$ de área. Esse templo foi fundado por Provisão concedida em 14 de dezembro de 1758, cujas obras se iniciaram em 1760 e foram concluídas em 1781. O trecho do Caminho de Capueraçu, entre a travessa de São Domingos até o Campo de Santana, ficou conhecido como rua São Gonçalo Garcia. Em 1854, após a aprovação das autoridades eclesiásticas, fundiram-se as duas Irmandades dando origem a Venerável Confraria dos Gloriosos Mártires São Gonçalo Garcia e São Jorge. No Mapa 5, de 1760, já se encontram implantadas essas duas igrejas.

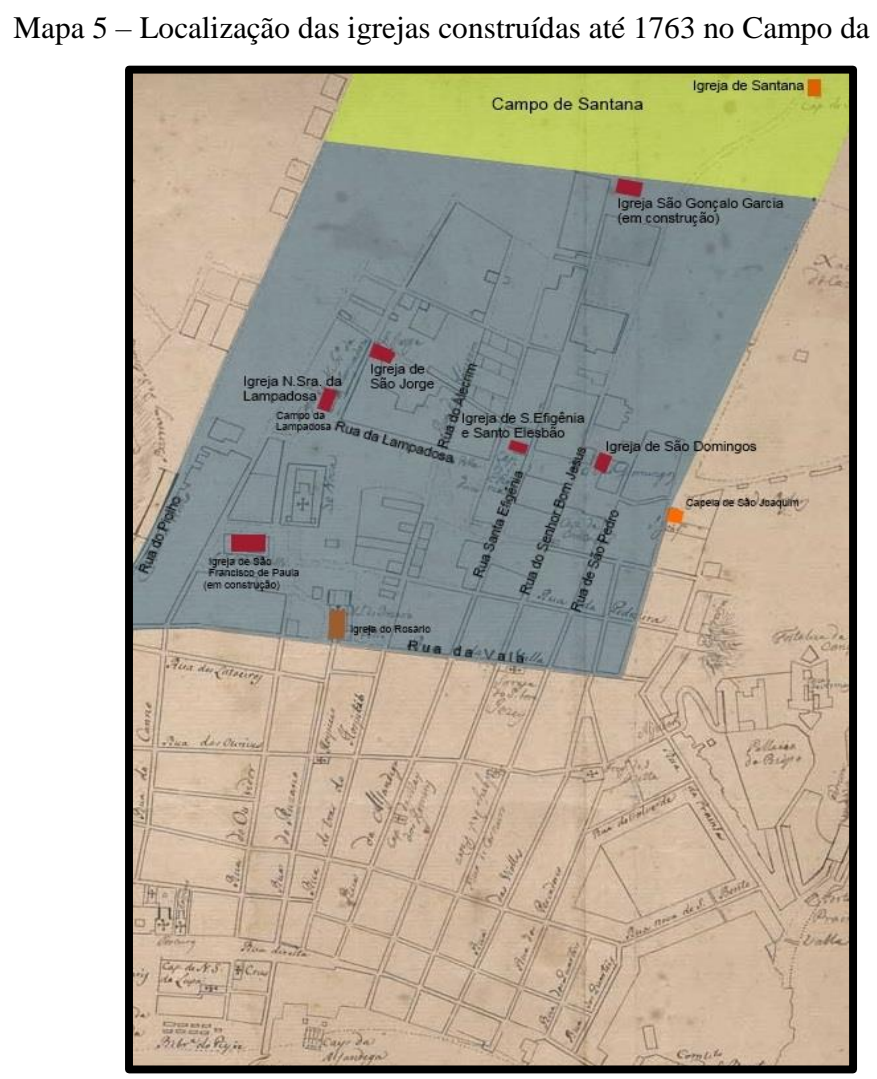

Elaborado por Teixeira, C. a partir da Planta da cidade do Rio de Janeiro - entre 1758 e 1760. Disponível em: <http://objdigital.bn.br/acervo_digital/div_cartografia/cart309972.htm> 
Com relação ao conceito de territorialidade, percebe-se que esta também influi na ordenação do território religioso quer por fragmentação de um território, desmembramento ou coesão com outros territórios. Isso ocorre por questões políticas, econômicas e religiosas, sempre na preocupação de controlar e manter a gestão da área (ROSENDAHL, 2012). As estratégias de controle deverão ser aliadas à dimensão política e sócio-religiosa do grupo social envolvido. Tal fato ocorreu no caso da Irmandade de São Gonçalo Garcia e da Irmandade de São Jorge, que no processo de coesão, ocupando um único território, exerceram o poder de construção de identidade religiosa para manutenção e controle desse território religioso. Nesse caso para os irmãos de São Jorge seria importante permanecer em território próximo ao seu, para continuar mantendo suas práticas religiosas junto a outra Irmandade com interesses afins. Juntas conseguiram assegurar o controle sobre o território religioso, mobilizando um número significativo de fiéis e, ao longo do tempo, foi se consolidando como um dos templos mais populares da cidade. A localização foi a estratégia utilizada para a perpetuação da prática.

$\mathrm{Na}$ região de entorno dessas igrejas construídas pelas Irmandades até o ano de 1763, pelo levantamento realizado por Gonçalves (2004, p. 295) sabe-se que, além das chácaras existentes, vivia "uma população de humildes operários e trabalhadores em casebres e palhoças." A concessão de terrenos em área desvalorizada do centro da cidade acarretou para os membros dessas Irmandades de pretos e pardos, além da construção do próprio templo, o trabalho de drenagem e aterro de pântanos e a implantação de caminhos para acesso ao mesmo. A partir do governo do Vice-reinado, com a capital e seu aparato administrativo instalada na cidade do Rio de Janeiro, verificou-se que o impulso inicial dado por essas construções religiosas acarretou em políticas públicas voltadas para esse novo espaço urbano.

\section{Considerações finais}

As Ordens Leigas analisadas se implantaram na região do Campo da Cidade porque receberam o terreno como doação ou pelo atrativo de preço mais baixo. Independente da razão que os motivou, o essencial é que todas as Ordens Leigas apresentadas se consubstanciaram em um importante espaço de vivência religiosa, social e política que viria a ultrapassar os limites do seu território religioso. A territorialidade de cada Ordem Leiga com seus espaços ocupados por celebrações, seus trajetos pelas ruas em dias de festa e procissão, fez com que os acessos e a área circunvizinha ao templo fossem melhorando de qualidade a cada ano, atraindo a atenção do poder público que, posteriormente, viria a investir recursos em melhoramentos para a região. O território 
religioso

funcionou

como

pólo

centralizador em torno do qual a região de expansão natural do núcleo central foi se estruturando.

Pela visualização dos mapas, em ordem cronológica, constatou-se que a presença da igreja de propriedade da Ordem Leiga ocasionou um avanço da malha urbana em direção seu território religioso. Verificou-se que o alinhamento de logradouros que já existiam foi prolongado até o local da igreja. No exercício de sua territorialidade, cada Ordem Terceira ou Irmandade foi envolvendo e cativando um número maior de fiéis. Tal fato contribuiu para a expansão territorial da Igreja Católica e da própria cidade do Rio de Janeiro.

\section{Notas}

${ }^{1}$ Arquiteta e urbanista. Doutora em História Política pelo PPGH/UERJ. Mestre em Arquitetura e Urbanismo pelo PPGAU/UFF. Email: claudiabarbosat14@gmail.com

${ }^{2}$ Ordens Terceiras e Irmandades.

${ }^{3}$ A estrutura da não concluída Sé Nova se tornou um prédio onde se instalou a Academia Militar, depois a Escola Central e, por fim, a Escola Politécnica. Atualmente as instalações são ocupadas pelo Instituto de Filosofia, História e Ciências Sociais da Universidade Federal do Rio de Janeiro.

${ }^{4}$ O mangue de São Diogo ou Saco de São Diogo, como era denominado no século XVIII, se estendia das proximidades do Campo de Santana até a Baía de Guanabara, cortando a atual rua Francisco Bicalho.

5 Cordeamento era o processo de execução dos traçados das ruas por meio de cordas e estacas. Devido à precariedade do material utilizado, esse traçado não se mantinha por muito tempo a não ser que fossem construídas as edificações do logradouro no alinhamento estabelecido pelas cordas.

\section{REFERÊNCIAS BIBLIOGRÁFICAS}

BARREIROS, Eduardo Canabrava. Atlas da evolução urbana do Rio de Janeiro. Rio de Janeiro: IHGB, 1965.

CAVALCANTI, Nireu. O Rio de Janeiro Setecentista. Rio de Janeiro: Zahar, 2004.

COARACY, Vivaldo. Memórias da cidade do Rio de Janeiro: quatro séculos de histórias. 4. ed. Rio de Janeiro: Documenta Histórica, 2008.

FAZENDA, José Vieira. Antiqualhas e Memórias do Rio de Janeiro. Rio de Janeiro: Imprensa Nacional, 1921.

GONÇALVES, Aureliano Restier. Cidade de São Sebastião do Rio de Janeiro: terras e fatos. Rio de Janeiro: Secretaria Municipal das Culturas, Arquivo Geral da Cidade do Rio de Janeiro, 2004.

ROSENDAHL, Zeny. Primeiro a obrigação, depois a devoção: estratégias espaciais da Igreja Católica no Brasil de 1500 a 2005. Rio de Janeiro: EdUERJ, 2012.

Espaço e Cultura: Pluralidade Temática. Rio de Janeiro: EdUERJ, 2008.

Difusão e territórios diocesanos no Brasil: 15511930. Revista Eletrônica de Geografia y Ciências Sociales Vol X, num 218, Universidad de Barcelona, 2006.

SACK, Robert David. Human territoriality: its theory and history. Cambridge: Cambridge University Press, 1986. 


\title{
THE TERRITORIALITY OF LAY ORDERS AND THE URBAN CONFIGURATION OF THE RIO DE JANEIRO CITY IN THE CENTURY XVIII
}

\begin{abstract}
The urban configuration of the central area of Rio de Janeiro city, among others, was involved by the religiosity of its inhabitants, who in many cases congregated themselves in religious associations that had exerted an important social, economic and political paper in Carioca's society in eighteenth-century. The present article has for objective to point these associations known as Laypeople Orders - Third Orders and Brotherhoods - that in the exercise of its territoriality had blunted as one of the agents of formation of the downtown urban mesh out of the limits established until the end of eighteenth-century. In such a way, the strategical actions of these associations were pointed that with its devocionals practical as processions, parties and pilgrimages, would have appropriated the territory of Campo da Cidade, region of expansion of the central nucleus.
\end{abstract}

Keywords : Laypeople Orders. Territoriality. Rio de Janeiro. Eighteenth-century. 